\title{
Pancreatic Ascites and Pleural Effusion
}

\author{
K. Prakash \\ PVS Memorial Hospital, \\ Kaloor, Kochi, Kerala, \\ India
}

\section{Introduction}

Pancreatic ascites or internal pancreatic fistulae and pancreatic pleural effusion are rare complications of pancreatitis. This can occur in the clinical setting of an acute pancreatitis and more commonly as a complication of chronic pancreatitis ${ }^{1}$. This is an uncommon clinical condition; often the patients are sick and nutritionally compromised. Pancreatic ascites was first reported in the literature in 1953 when Smith described two cases of ascites associated with chronic pancreatitis ${ }^{2}$.

\section{Definition}

Exact definition to diagnose this condition is not clear in the literature. Pancreatic ascites / pleural effusion is characterised by accumulation of high amylase fluid in the peritoneal cavity/pleural cavity due to leakage of pancreatic juice from a disrupted pancreatic duct and a diagnosis is usually made once the aspirated fluid is high in protein $(>3 \mathrm{~g} / \mathrm{dl})$ and high in amylase $(>1000 \mathrm{IU} / \mathrm{L})^{3}$.

\section{Aetiology and pathogenesis}

Pancreatic ascites/pleural effusion can occur due to a) rupture of a pseudocyst into peritoneal cavity or to mediastinum and pleura or b) due to the disruption of a main pancreatic duct during the natural course of chronic pancreatitis ${ }^{3}$. Pancreatic leak occurs in $3.5 \%$ of patients with chronic pancreatitis and $6 \%$ to $14 \%$ of patients with pancreatic pseudocyst 4,5 . The pathogenesis of the serous cavity effusion is different in acute and chronic pancreatitis setting. In acute pancreatitis, mostly in alcoholic pancreatitis, there is enough inflammatory reaction around the pancreas with neighbouring structures like stomach and transverse colon to form a pseudocyst. This can rupture into peritoneal cavity or mediastinum and to pleural cavity subsequently to produce ascites or pleural effusion respectively. Similar type of duct disruptions may also occur in acute setting in blunt abdominal trauma, biliary pancreatitis, and rupture of duplication cyst and rarely after pancreatic surgery or splenectomy1,6.

In the setting of chronic pancreatitis, leakage is seen in up to $80 \%$ of cases from a communicating pseudocyst due to ductal stricture and less commonly (20\%) due to duct 
disruption itself 3,7 . This has also been described in the setting of tropical calcific pancreatitis as well from duct disruptions and leaking pseudocyst ${ }^{8}$. Once the amylase rich fluid enters serous cavity, since the enzymes are not activated it does not produce digestion, instead it produces irritation resulting in outpouring of albumin resulting in high-albumin ascites. This accumulation of amylase rich fluid is usually massive before it produces symptoms due to its pressure effects. The amylase in the fluid can get reabsorbed into the blood stream and produce elevation of serum amylase as well. It has been also reported in one series that pancreatic ascites or effusions may present with indolent symptoms and up to $42 \%$ of patients gave no history of pancreatic disease ${ }^{9}$.

\section{Diagnosis and evaluation}

Aim of the investigations in patients with pancreatic ascites are a). Overall assessment of patient's general and nutritional status and b). To delineate the pancreatic ductal anatomy and to locate the possible site of leak. These patients should have a haemogram, serum protein, and albumin and amylase value and coagulation profile. Upper GI endoscopy to rule out peptic ulcer or periampullary malignant disease and ultrasonography should be done. The diagnosis is usually confirmed with ascitic fluid assay. Usually the ascitic/pleural fluid contains high protein $>3 \mathrm{~g} / \mathrm{dl}$ and high amylase $>1000 \mathrm{IU} / \mathrm{ml}$. Ascitic fluid assay should also be done to rule out other differential diagnosis like cirrhosis of liver or disseminated malignancy.

The localization of site of rupture or leak of main pancreatic duct is essential for planning therapy. Earlier, intraoperative pancreatography was the mainstay of localisation which is superseded largely by Endoscopic Retrograde Pancreatography (ERP) in recent years. However, these procedures are invasive and correct delineation of the duct anatomy and leak may not be feasible in all cases due to strictures or due to technical reasons. Demonstration of pancreatic duct leak by non invasive methods offer advantages like avoiding a sedation or anaesthesia, avoiding risk of introducing infection during injection of dye to the pancreatic duct. Non invasive investigations like CT scan helps in indentifying peripancreatic collections and details of the parenchyma of the pancreas. The details of pancreatic parenchyma, duct size, stones, strictures and psuedocysts are well displayed in a CT scan. The identification of site of leak from the pancreatic duct is possible in nearly half of the patients ${ }^{10}$. Magnetic Resonance Imaging (MRI) has also been reported to give good details of pancreatic parenchyma, details of the duct and details of the fistula11, 12. In MRP, high signal intensity of static or slowly flowing liquids is observed in T2 weighted images. Hence the pancreatic duct and the fistulous tract is displayed as high-signal intensity structure which helps in identifying the communication like pancreaticopleural fistula. The details of the pancreatic parenchyma and duct structural changes are also well displayed in MRI. Moreover, in MRI no contrast material is injected and there is no risk of infection in comparison with ERP. In a recent study ${ }^{13}$, the ability of helical CT scan and Magnetic Resonance Pancreatography (MRP) when performed alone in identifying the site of duct disruption were 50 and $67 \%$ respectively. When these two modalities were combined the exact site of rupture of duct was observed in $94 \%$ of cases. Hence, a combination of imaging modalities helps to improve the details of the duct disruption,the site of leak and the details of the pancreatic parenchyma which is essential in planning of therapy. 


\section{Management}

Management of these patients are challenging due to the compromised nutritional state, generalized weakness, diabetes mellitus and disease related factors like multiple strictures, large stones and inflammatory mass. All patients with a diagnosis of pancreatic ascites or pleural effusion should be assessed for their nutritional status. This is important as the morbidity and mortality of the various modes of treatment is related to the patient's general condition. These patients may be managed by conservative approach, endoscopic therapy and by surgical therapy. This may be done in using an algorithm depending upon patient's clinical condition 8 . (Table 1)

\section{Algorithmic approach to the management of Pancreatic ascites}

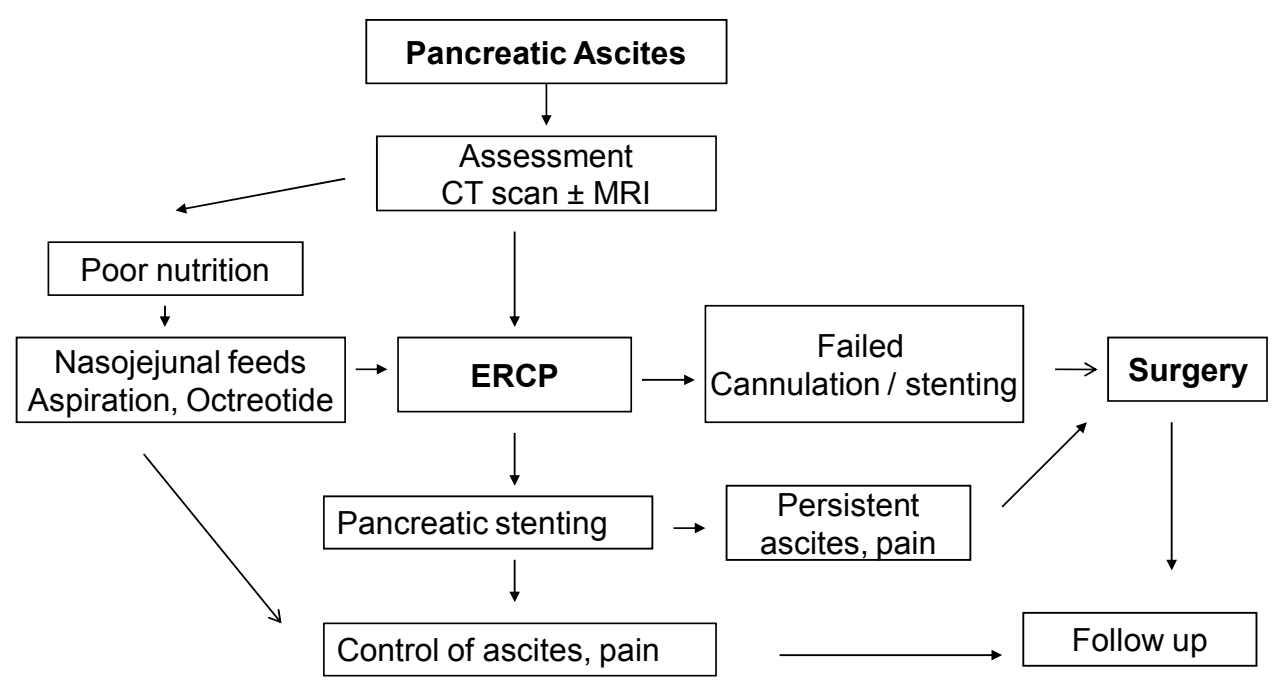

Table 1. Algorithmic approach to the management of pancreatic ascites.

\section{Conservative treatment}

Initial trial of conservative treatment is indicated in almost all patients. It was generally believed that there is high risk for mortality while the patients are on conservative therapy, which is due to poor nutritional management and assessment in the initial reports. Though an old series ${ }^{14}$ had reported high mortality with conservative therapy, the progress of the patient can be safely monitored on conservative therapy in current daily practice. The key steps in the conservative management of the pancreatic ascites or pleural effusion are a). Rest to the pancreas and to limit pancreatic exocrine stimulation by keeping the patients nil orally, b). Nutritional support by means of nasojejunal feeds or by Total Parenteral Nutrition $(\mathrm{TPN}), \mathrm{c})$. Use of drugs likes to decrease pancreatic secretion d). Drainage of fluid by aspiration, drainage of ascites or by tube thoracocentesis. So patients are kept nil per oral and nutritional support should be planned on case to case basis. There is no significant difference between enteral or parenteral feeds on pancreatic exocrine secretion clinically 15 . However, these patients are often nutritionally compromised and have nausea, anorexia and 
poor tolerance to feeds due to exocrine insufficiency. Enteral nutritional support should be attempted whenever possible as it maintains mucosal integrity and prevents bacterial translocation. Nasojejunal feeds have a theoretic benefit as it prevents stimulation of pancreas and minimises fistula output. In patients who do not tolerate enteral feeds well or those with catabolic response TPN should be used either alone or along with enteral feeds.

Serous cavities should be emptied to promote approximation of serosal surfaces by drainage of ascitic/pleural fluid. Repeated aspiration of ascites or drainage of the ascites with the tube near the pseudocyst helps to drain the fluid by a controlled fistula. Similarly, aspiration or tube drainage should be done according to be patient's symptoms. Along with above measures, use of drugs with the aim to decrease the pancreatic exocrine secretion like somatostatin or octreotide also have a role in improving the pancreatic leak ${ }^{15-17}$. These drugs have been noted to decrease the fistula output (often within 24 hours of treatment) and accelerate the fistula closure. Depending upon the clinical situation a conservative therapy with above measures for 3-4 weeks helps in resolution of pancreatic leak in $25-60 \%$ of cases ${ }^{17,18}$. Patients with low sodium levels, albumin levels and those with a high fluid to serum protein levels had high chance for treatment failure ${ }^{18}$. Other agents attempted in closure of pancreatic leak are fibrin glue and nafamostat mesilate with variable results. Patients those who fails to respond to conservative measures or those patients who are symptomatic should undergo endotherapy or surgery.

\section{Endotherapy}

Endoscopic Retrograde Pancreatography (ERP) is the key step in planning of endoscopic treatment. ERP helps to delineate the anatomy of the duct, presence of strictures and site pancreatic leak (Figure 1). The principles of endotherapy include pancreatic sphincterotomy and placement of a transduodenal pancreatic stent across the site of ductal leak. This helps to obliterate the high-pressure gradient at the pancreatic sphincter, allowing preferential flow of pancreatic secretions along a low resistance path to the duodenum, thereby allowing the site of leak to heal. This has been reported in many series $6,8,13,19,20$. It has been observed that a sphincterotomy and placement of stent close to the fistula, even if the stent could not be advance beyond the site of leak helps to heal the fistula or stabilizes patients clinical condition 8 . Other endoscopic approaches which are practised are endoscopic placement of nasopancreatic drainage ${ }^{21}$ and endosonography guided pancreatogastrostomy 22 . Nasopancreatic drainage alone has been used instead of placement of pancreatic duct stenting in treatment of pancreatic ascites 22 . The authors have reported nearly $90 \%$ of success in placement of nasopancreatic drain and disappearance of pseudocyst and ascites were observed on 4-6 weeks. Nasopancreatic drains allow repeated pancreatography to assess the progress of therapy and healing of the duct. This method provides the option of flushing of the drain to clear the blocks and allows removal of the drain once the duct disruption is healed. The disadvantages of this method are the discomfort to the patients due to the nasal tube and risk of accidental dislodgement.

The success of endotherapy ranges from $50-90 \%$ depending upon the duct changes ${ }^{8,19-21}$. Success of endoscopic treatment was based on three factors in this study a) ability to pass the stent across the site of disruption of the duct, b) absence of strictures and stones and c) ability to traverse the stricture. Those patients who had only partial relief of symptoms and those with failed endotherapy would require surgery. 


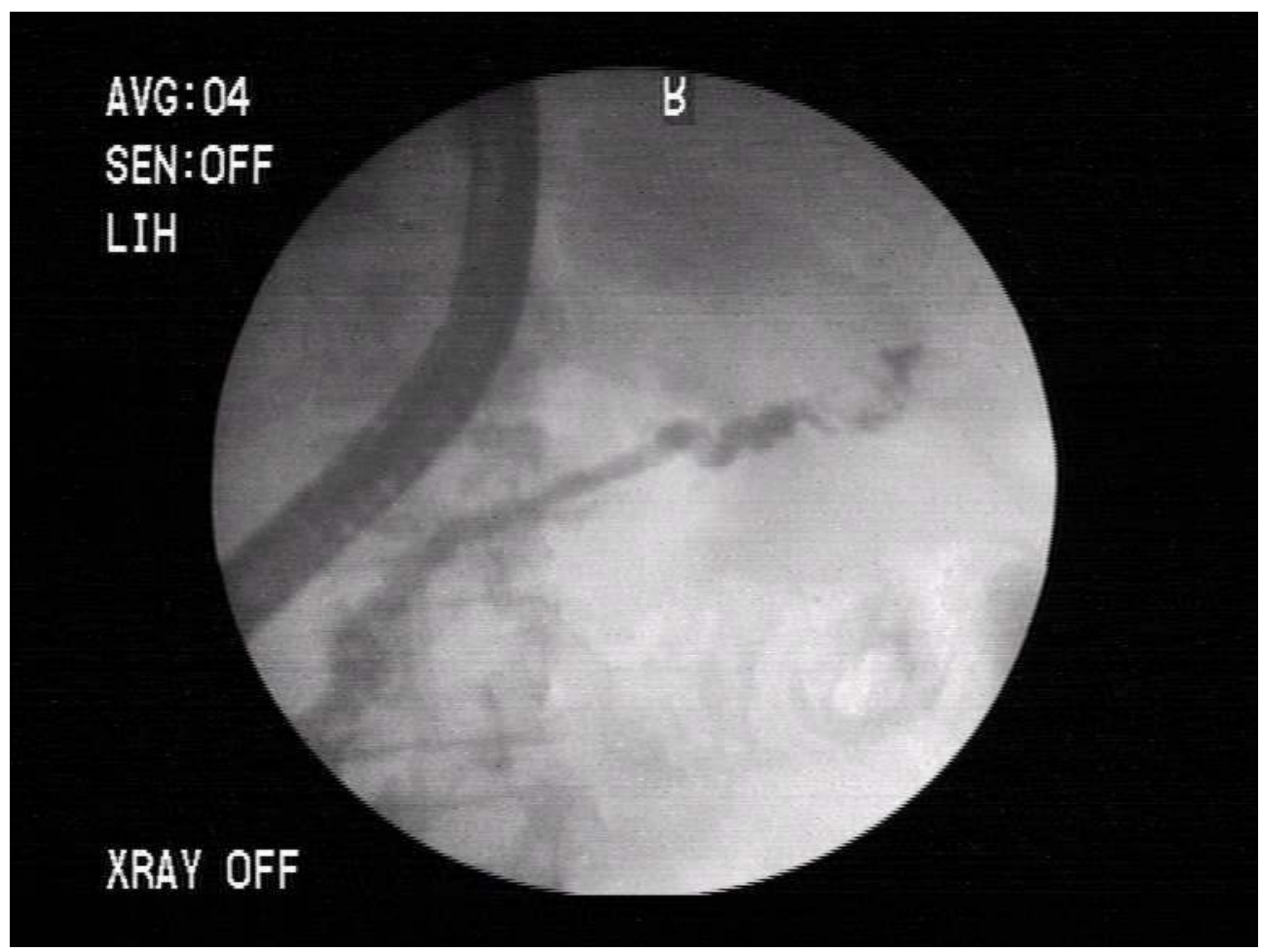

Fig. 1. Endoscopic retrograde pancreatography showing leak of dye from tail duct.

\section{Surgery}

The surgical intervention is planned according to the ductal anatomy and site of leak (figure 2). Aims of the surgery in patients with chronic pancreatitis with pancreatic ascites are to a) wide drainage of pancreatic duct, often with a Lateral Pancreatojejunostomy (LPJ) b) removal of pancreatic stones and ductal strictures and c) drainage of the cysts and external drainage of abscess.

Patients with chronic pancreatitis with large duct $(>7 \mathrm{~mm})$ should undergo wide drainage of pancreatic duct often with a lateral panctreatojejunostomy and removal of pancreatic stones and ductal strictures $5,7,8$. Specific repair of the site or disruption is often unnecessary; however the area of disruption should be included in the anastomosis. Similarly, a mature pseudocyst also can be incorporated in the anastomosis. In patients with normal sized duct, identification of the site of leak is very important. In those with distal leak, a distal pancreatectomy with or without splenectomy is a good option. Spleen preservation is often difficult in these patients due to dense adhesions and inflammatory process. If the inflammation and fibrosis is significant a medial to lateral approach in distal pancreatectomy may be used to avoid excessive bleeding. 


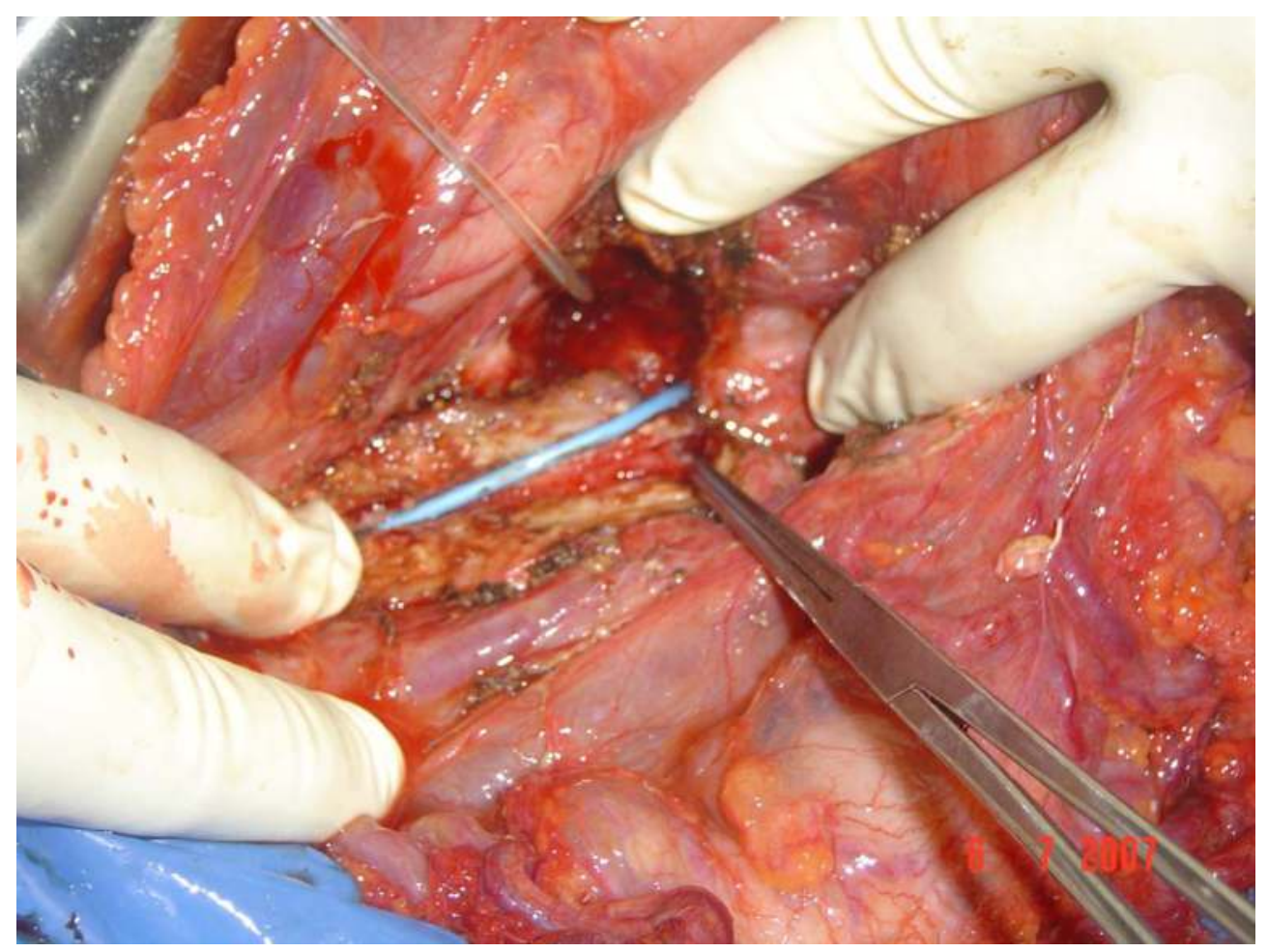

Fig. 2. Operative picture showing disruption of pancreatic duct in the body region with pancreatic stent in situ coming out through the site of disruption.

In those with leak from the neck region Roux -en-Y anastomosis to the fistula site or pancreatogastrostomy has been described. In those patients with disconnected duct syndrome, often secondary to acute pancreatic necrosis, there is often a loss of tissue near the genu with fistula from either distal or proximal duct. A Roux-en-Y anastomosis to the distal duct and closure of the proximal duct or distal pancreatectomy with closure of proximal duct may be performed according to the clinical situation. In patients with long fistulous tract to skin, dissection of fistula and fistula-enterostomy has been reported with varying results ${ }^{23}$. Surgery for pancreatic ascites is often difficult due to the dense inflammatory process in the peripancreatic tissue, mesentery and due to the presence of pseudocysts and often identification of site of leak is difficult and cystojejunostomy to the leaking cyst is also an effective option ${ }^{24,25}$.

\section{Conclusion}

Pancreatic ascites or pleural effusion are rare complications of acute or chronic pancreatitis wherein there is leakage of pancreatic juice to a serous cavity from a disrupted pancreatic duct or leaking pseudocyst. Preoperative workup should be aimed at the nutritional assessment of the patient and the pancreatic ductal imaging using CT scan or MRI. An 
algorithmic approach may be adopted in managing this patients using conservative, endotherapy or surgical treatment according to the clinical scenario. A multidisciplinary approach of these modalities is essential for successful management of these patients.

\section{References}

Barish MA, Soto JA. MR cholangiopancreatography: techniques and clinical applications. AJR Am J Roentgenol 1997; 169:1295-1303.

Bhasin DK. Endoscopic transpapillary nasopancreatic drainage alone to treat pancreatic ascites and pleural effusion. - - J Gastroenterol Hepatol 2006; 21: 1059-64

Bracher GA, Manocha AP, DeBanto JR, Gates LK, Slivka A, Whitcomb DC, et al. Endoscopic pancreatic duct stenting to treat pancreatic ascites. Gastrointest Endosc 1999; 49: $710-5$.

Brooks JR. Pancreatic ascites. In: Brooks JR, editor. Surgery of the pancreas. Philadelphia: WB Saunders; 1983, p. 230-2.

Cameron JL. Chronic pancreatic ascites and pancreatic pleural effusions. Gastroenterology 74:134, 1978.

da Cunha JE, Machado M, Bacchella T, Penteado S, Mott CB, Jukemura J, et al. Surgical treatment of pancreatic ascites and pancreatic pleural effusions. Hepatogastroenterology 1995; 42: 748-51.

Dhar P, Tomey S, Jain P, Azfar M, Sachdev A, Chaudhary A. Internal pancreatic fistulae with serous effusions in chronic pancreatitis. Aus N Z J Surg 1996; 66: 608-11.

Eckhauser F, Raper SE, Knol JA, Mulholland MW. Surgical management of pancreatic pseudocysts, pancreatic ascites, and pancreatopleural fistulae. Pancreas 1991; 6: 566-75.

Francois E, Kahaleh M, Giovannini M, Matos C, Deviere J. EUS-guided pancreaticogastrostomy. Gastrointest Endosc 2002; 56: 128-33.

Fulcher AS, Capps GW, Turner MA. Thoracopancreatic fistula: clinical and imaging findings. J Comput Assist Tomogr 1999; 23: 181-7.

Kozarek RA, Ball TJ, Patterson DJ, Freeny PC, Ryan JA, Traverso LW. Endoscopic transpapillary therapy for disrupted pancreatic duct and peripancreatic fluid collections. Gastroenterology 1991; 100: 1362-70.

Kurumboor P, Varma D, Rajan M, Kamlesh NP, Paulose R, Narayanan RG, Philip M. Outcome of pancreatic ascites in patients with tropical calcific pancreatitis managed using a uniform treatment protocol. Indian J Gastroenterol. 2009; 28: 102-6.

Lipsett PA, Cameron JL. Internal pancreatic fistula. Am J Surg 163:216, 1992.

MacLauren IF. Pancreatic ascites. In: Howard JM, Jordan GL, Reber HA, editors. Surgical diseases of the pancreas. Philadelphia: Lea and Febigor; 1987. p. 591-602.

Martineau P, Shwed JA, Denis R. Is octreotide a new hope for enterocutaneous and external pancreatic fistulas closure? Am JSurg 1996; 172: 386-395.

Materne R, Vranckx P, Pauls C, Coche EE, Deprez P, Van Beers BE.. Pancreaticopleural Fistula. Diagnosis with magnetic resonance pancreatography. Chest 2000; 117:912914.

Moosa AR. Surgical treatment of chronic pancreatitis: an overview. Br J Surg 1987; 74: 661-7. 
Oktedalen O, Nygaard K, Osnes M. Somatostatin in the treatment of pancreatic ascites. Gastroenterology 1990; 99: 1520-1.

O'Toole D, Vullierme MP, Ponsot P, Maire F, Calmels V, Hentic O, Hammel P, Sauvanet A, et al. Diagnosis and management of pancreatic fistulae resulting in pancreatic ascites or pleural effusions in the era of helical CT and magnetic resonance imaging. Gastroenterol Clin Biol. 2007; 31:686-93.

Pai CG. Endoscopic treatment as first-line therapy for pancreatic ascites and pleural effusion. - - J Gastroenterol Hepatol 2009; 24: 1198-202.

Parekh D, Segal I. Pancreatic ascites and effusion: risk factors for failure of conservative therapy and role of octreotide. Arch Surg 1992; 127: 707-12.

Qin HL, Su ZD, Zou Y, Fan YB. Effect of parenteral and enteral nutrition combined with octreotide on pancreatic exocrine secretion of patients with pancreatic fistula. World J Gastroenterol 2004; 10: 2419-2422.

Sankaran S, Walt AJ. Pancreatic ascites, recognition and management. Arch Surg 1976; 111: 430-4.

Smith EB. Hemorrhagic ascites and hemothorax associated with benign pancreatic disease. Arch Surg 1953; 67:52-6.

Voss M, Ali A, Eubanks WS. Surgical management of pancreaticocutaneous fistula.J Gastrointest Surg 2003;7:542-6 


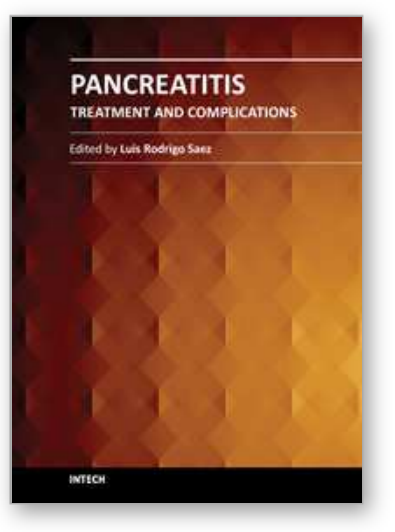

\author{
Pancreatitis - Treatment and Complications \\ Edited by Prof. Luis Rodrigo
}

ISBN 978-953-51-0109-3

Hard cover, 212 pages

Publisher InTech

Published online 02, March, 2012

Published in print edition March, 2012

Pancreatitis may be acute or chronic. Although they can be caused by similar aetiologies, they tend to follow distinct natural histories. Around $80 \%$ of acute pancreatitis (AP) diagnoses occur as secondary to gallstone disease and alcohol misuse. This disease is commonly associated with the sudden onset of upper abdominal that is usually severe enough to warrant the patient seeking urgent medical attention. Overall, 10 to $25 \%$ of AP episodes are classified as severe, leading to an associated mortality rate of 7 to $30 \%$. Treatment is conservative and consists of general medical support performed by experienced teams, sometimes in ICUs. Although most cases of acute pancreatitis are uncomplicated and resolve spontaneously, the presence of complications has significant prognostic importance. Necrosis, hemorrhage, and infection convey rates of up to $25 \%, 50 \%$, and $80 \%$ mortality, respectively. Other complications such as pseudocyst formation, pseudoaneurysm formation, or venous thrombosis increase morbidity and mortality to a lesser degree. The presence of pancreatic infection must be avoided.

\title{
How to reference
}

In order to correctly reference this scholarly work, feel free to copy and paste the following:

K. Prakash (2012). Pancreatic Ascites and Pleural Effusion, Pancreatitis - Treatment and Complications, Prof. Luis Rodrigo (Ed.), ISBN: 978-953-51-0109-3, InTech, Available from:

http://www.intechopen.com/books/pancreatitis-treatment-and-complications/pancreatic-ascites-and-pleuraleffusion

\section{INTECH}

open science | open minds

\section{InTech Europe}

University Campus STeP Ri

Slavka Krautzeka 83/A

51000 Rijeka, Croatia

Phone: +385 (51) 770447

Fax: +385 (51) 686166

www.intechopen.com

\section{InTech China}

Unit 405, Office Block, Hotel Equatorial Shanghai

No.65, Yan An Road (West), Shanghai, 200040, China

中国上海市延安西路 65 号上海国际贵都大饭店办公楼 405 单元

Phone: +86-21-62489820

Fax: $+86-21-62489821$ 
(C) 2012 The Author(s). Licensee IntechOpen. This is an open access article distributed under the terms of the Creative Commons Attribution 3.0 License, which permits unrestricted use, distribution, and reproduction in any medium, provided the original work is properly cited. 